\title{
Haemophili from eyes
}

\author{
H. R. INGHAM AND D. C. TURK \\ From the Public Health Laboratory and the University and Royal Victoria Infirmary Microbiology \\ Department, Newcastle upon Tyne
}

SYNOPSIS The identity of haemophili isolated in our laboratories from eye swabs was investigated. Ten out of 114 strains belonged to capsulated types of $H$. influenzae. Seventy-six strains were submitted to tests for the identification of $H$. aegyptius (the Koch-Weeks bacillus), but none was proved to belong to this species. An unexpectedly high proportion of the haemophilus strains, including most of those with capsules, came from patients with lachrymal duct obstruction.

Most clinical bacteriologists are familiar with the problem of naming an organism which they would unhesitatingly call Haemophilus influenzae if it had come from the respiratory tract but which in fact came from an eye. Should such an organism be called $H$. aegyptius? This is the modern name for the bacillus seen by Koch (1883) in conjunctivitis exudates in Egypt, cultured by Weeks (1886), and long known as the Koch-Weeks bacillus. For many years it was not clear what characters, if any, distinguished this organism from the influenza bacillus' described by Pfeiffer in 1892. The situation was considerably clarified by Pittman and Davis (1950) when they reported that 'the Koch-Weeks bacillus, Hemophilus aegyptius, is a distinct species that can be separated from Hemophilus influenzae by serological means and, to a certain extent, by growth characteristics and biochemical reactions', and also by the ability of $\boldsymbol{H}$. aegyptius suspensions to agglutirrate red blood cells (Davis, Pittman, and Griffitts, 1950). However, the same workers found that by no means all the haemophili apparently responsible for endemic and epidemic 'pink eye' in Texas were $H$. aegyptius; among 61 strains they found three capsulated and at least 12 non-capsulated strains of H. influenzae (Davis and Pittman, 1950). Huet (1956) studied haemophili isolated from cases of seasonal conjunctivitis in Tunisia; he found that a few strains were capsulated and conformed to the recognized capsulated types of $H$. influenzae, but the majority of isolates were not capsulated and he could not be sure to which of the two species they belonged. By gel-diffusion antigenic analysis of sonically disintegrated bacteria Olitzki and Sulitzeanu (1959) showed that six haemophilus strains, isolated in Israel and designated $H$. aegyptius, had more antigens in common with American $\boldsymbol{H}$. aegyptius strains supplied by Dr Pittman than with $H$. influenzae strains; but there were considerable antigenic similarities between all of the haemophilus strains tested, their separation into two antigenically distinct species was by no means clear-cut, and the authors did not say whether their six local strains were representative of haemophili isolated from eyes in Israel or were selected by preliminary testing. The genetic transformation studies of Leidy, Jaffee, and Alexander (1965) indicate a close affinity between $H$. aegyptius and $H$. influenzae.

It is clear that the literature does not justify the common assumption that haemophili from eyes can be regarded as different from those in the respiratory tract and should be classified as $H$. aegyptius. Indeed, so far as we are aware nobody has shown that $H$. aegyptius occurs in Britain. We report here a study of 114 haemophilus strains isolated in our laboratories in the course of routine examination of eye swabs from patients attending Newcastle hospitals.

\section{MATERIALS}

HAEMOPHILUS STRAINS Since 1962 non-haemolytic haemophili isolated in the Bacteriological Laboratory of the Royal Victoria Infirmary from clinical specimens of all kinds, including eye swabs, have been tested to see whether they belonged to any of the capsulated types of $H$. influenzae. The Public Health Laboratory receives a much larger number of eye swabs, mostly from the Ophthalmic Department of the Newcastle General Hospital, and haemophili isolated from these were included in the survey from January 1966 until the present study ended in October 1967. In general only one isolate per patient has been included in this report, but in two cases non-capsulated haemophili were isolated from patients whose previous eye swabs had yielded capsulated $H$. influenzae, and in such circumstances the isolates were regarded as different strains. Thus our 114 strains came 
from only 112 patients. Clinical information about these patients is considered below, in the Results section. Strains isolated in either laboratory from March 1966 onwards, together with a few others (most of them capsulated) isolated earlier and preserved in freezedried cultures, were submitted to a series of tests which were intended to identify $H$. aegyptius; 76 of the 114 strains were tested in this way. All of the 114 strains consisted of small Gram-negative bacilli or cocco-bacilli, which formed small or minute colonies on blood agar in the absence of other organisms but showed satellitism in the vicinity of staphylococci or other sources of $\mathrm{V}$ factor. Their X-factor requirements were not tested. No haemolytic haemophili were isolated from eyes during this study, although we commonly encounter such organisms in cultures from respiratory tract specimens.

STANDARD $H$. aegyptius STRAIN AND ANTISERUM Dr Margaret Pittman very kindly supplied us with freezedried cultures of her $\boldsymbol{H}$. aegyptius strain 180a (Pittman and Davis, 1950) and with an ampoule of freeze-dried rabbit antiserum for that strain.

\section{METHODS}

CULTURE MEDIA Levinthal stock and Levinthal agar were made as described by Turk and May (1967), using the Oxoid ingredients mentioned by them as possible alternatives. Levinthal broth was made by mixing one part of Levinthal stock with three parts of meat-infusion broth. Broth for testing indole production was made by mixing equal parts of Levinthal stock and peptone water.

COLONIAL AND MICROSCOPIC MORPHOLOGY The sizes and appearances of colonies on Levinthal agar were observed after 18 hours' incubation at $37^{\circ} \mathrm{C}$, and Gramstained films were made from such cultures.

DETECTION AND TYPING OF CAPSULATED $H$. influenzae STRAINS Such strains were detected by the typical iridescence of their colonies on Levinthal agar and were typed by slide-agglutination and capsule-swelling tests, using Hyland Laboratories typing sera. Details of these procedures have been given by Turk and May (1967).

INDOLE PRODUCTION Cultures in $3 \mathrm{ml}$ volumes of the medium described above were incubated at $37^{\circ} \mathrm{C}$ for 24 hours. In this rich medium all strains gave heavy growths within that period. Indole was detected by adding Ehrlich's rosindole reagent.

hAEMAGglutinAtion TESTS Davis et al (1950) carried out their haemagglutination tests in tubes and apparently used live cultures. We modified their technique so that Perspex haemagglutination trays could be used. Preliminary experiments with $H$. aegyptius $180 \mathrm{a}$ and with a number of the local strains showed that killing broth cultures with formalin did not alter their haemagglutinating power. Our subsequent routine procedure was to incubate $1 \mathrm{ml}$ Levinthal broth cultures at $37^{\circ} \mathrm{C}$ for 24 hours and then add $0.02 \mathrm{ml}$ of formalin to each culture. They were allowed to stand for at least 10 minutes before use, and if not required immediately they were stored in a refrigerator. For the test $0.04 \mathrm{ml}$ of neat culture was placed in one depression of a haemagglutination tray and $0.04 \mathrm{ml}$ amounts of two-fold dilutions of the culture in buffered saline $(p H$ 7.3) were prepared in neighbouring depressions. Amounts, each of $0.04 \mathrm{ml}$, of a $0.5 \%$ saline suspension of washed human red blood cells were then added to each of the depressions, which thus contained culture in final dilutions of $1: 2,1: 4,1: 8$, etc. The bacteria and red cells were well mixed by gentle shaking, and the tile, wrapped in plastic sheeting to reduce evaporation, was placed in a refrigerator at $4^{\circ} \mathrm{C}$ overnight. Next morning it was removed from the refrigerator and gently shaken to resuspend the red cells, which were then examined with a hand lens to see whether they had been agglutinated. $H$. aegyptius $180 \mathrm{a}$ was included in each batch of strains tested.

HAEMAGGLUTINATION INHIBITION TESTS Bacterial strains which gave positive results in the haemagglutination test were further investigated by preparing duplicate sets of culture dilutions and adding $0.04 \mathrm{ml}$ amounts of a $0.5 \%$ red cell suspension to one set as before, but adding to the other set $0.02 \mathrm{ml}$ amounts of diluted $H$. aegyptius antiserum followed by $0.02 \mathrm{ml}$ amounts of a $1 \%$ red cell suspension. The rest of the procedure was as already described.

BACTERIAL AGglutination TESTS Spontaneous agglutination of bacterial suspensions was a serious difficulty. Davis and his colleagues had similar troubles, but only with strains which they considered to be $H$. influenzae (personal communication, Dr Pittman). Lowering the electrolyte concentration of the suspending fluid gave stable suspensions, but only if carried to a level at which agglutination of $H$. aegyptius $180 \mathrm{a}$ by its homologous serum was considerably impaired. The results given below were obtained by using the least unsatisfactory of the various procedures that we tried. It consisted of incubating $5 \mathrm{ml}$ Levinthal broth cultures at $37^{\circ} \mathrm{C}$ for 24 hours and then placing them in a $56^{\circ} \mathrm{C}$ water bath for 45 minutes, depositing the bacteria by centrifugation, and resuspending them in buffered saline $(p H$ 7.3) at a concentration of approximately $2 \times 10^{\circ}$ per ml. Agglutination tests were carried out by mixing $0.1 \mathrm{ml}$ volumes of serum dilutions and of bacterial suspensions in Dreyer's tubes and placing these, together with control tubes containing saline instead of serum, in a $37^{\circ} \mathrm{C}$ water bath overnight. In the presence of an agglutinating concentration of its homologous antiserum $H$. aegyptius $180 \mathrm{a}$ gave a granular deposit at the bottom of the tube, with a clear supernatant. Suspensions which agglutinated even in the control tubes usually formed floccular agglutinates that adhered to the sides of the tubes and were easily resuspended and broken up by light tapping of the tubes.

\section{RESULTS}

MORPHOLOGY The colonies formed on Levinthal agar by $H$. aegyptius 180 a were considerably smaller than those of any of the local strains, though this 
difference became less marked after the $H$. aegyptius had been repeatedly transferred from one plate of this medium to another. In films made from 18hour Levinthal agar cultures $H$. aegyptius $180 \mathrm{a}$ was definitely bacillary, whereas all of the 76 local strains so examined were coccobacillary.

CAPSULATED $H$. influenzae Of the 114 local strains 10 produced iridescent growth on Levinthal agar and gave the serological reactions of capsulated $\boldsymbol{H}$. influenzae types: one type a, eight type b, and one type e.

INDOLE PRODUCTION Positive reactions were given by $49(73 \%)$ of 67 non-capsulated and by seven of nine capsulated strains tested. The type $e$ and one of the type b $H$. influenzae strains gave negative reactions, and one type $b$ strain was not tested.

HAEMAGGLUTINATION AND BACTERIAL AGGLUTINATION TESTS These were applied to the $H$. aegyptius $180 \mathrm{a}$ (repeatedly) and to 76 local strains, with the results shown in the Table. In order to conserve the available supply, the $H$. aegyptius antiserum was used only in single dilutions in tests for inhibition of haemagglutination and in most of the bacterial agglutination tests. Its agglutinating titre for its homologous strain was 320 .

The three local haemagglutinating strains were not capsulated; only one of them was indole-positive. Of the 10 strains that agglutinated in serum but not in the control tubes, two failed to agglutinate when the test was repeated; four gave only an easily dispersed floccular agglutination with serum at 1:40 and none with higher dilutions; and the remaining four gave granular agglutination with $H$. aegyptius serum at 1:40 and in two cases also at $1: 80$ dilution, but these results could be reproduced by using serum which came from an unimmunized rabbit and failed to agglutinate $H$. aegyptius $180 \mathrm{a}$.

CLINICAL DATA This investigation was primarily concerned with the nature of the haemophili that we isolate from eyes, rather than with their incidence and pathogenicity. We did not attempt to collect clinical data about the patients from whom the organisms came. However, a number of interesting points arise from looking at the information which reached us on the forms accompanying the swabs.

Of the 108 patients whose ages were given, 55 were under 1 year old and 83 under 7 years old. There were no older children or adolescents, and only 10 patients between the ages of 21 and 60 years, but there were 15 who were more than 60 years old. Both laboratories provide bacteriological services for all departments of large general hospitals, and the high proportion of young children is not due to a disproportionate contribution of swabs from paediatric departments; indeed, most of the patients at all ages were under the ophthalmologists, and the age distribution of the patients in our series is by no means a reflection of the types of patients from whom we receive eye swabs.

There were 93 patients about whose clinical conditions we received some information. Fifty-six of them were under 2 years but over 2 months old; of these, 23 had diagnoses of congenital lachrymal duct obstruction or of recurrent or chronic dacrocystitis (implying duct obstruction), and another 14, who had had watery or purulent eye discharges since birth or very soon afterwards, may well have belonged to the same group. The capsulated type a $H$. influenzae and six of the eight type b strains came from children in these categories. Two 2-yearold children and five adults (four of them over 65 years old) also had lachrymal duct obstruction. These figures probably underestimate the frequency of such obstruction in our series, as there were many

TABLE

HAEMAGgLUTINATION AND BACTERIAL AGGLUTINATION TESTS APPLIED to $\boldsymbol{H}$. aegyptius AND to LOCAL STRAINS

\begin{tabular}{|c|c|c|}
\hline Strain & Haemagglutination Test & $\begin{array}{l}\text { Bacterial Agglutination Test } \\
\text { (H. aegyptius serum diluted } 1: 40)\end{array}$ \\
\hline H. aegyptius & $\begin{array}{l}\text { Titre } 16 \text { or } 32 \text {, reduced } \\
\text { four-fold in the presence of } \\
\text { H. aegyptius serum } 1: 80\end{array}$ & $\begin{array}{l}\text { Granular type of agglutination, } \\
\text { none in control tube }\end{array}$ \\
\hline $\begin{array}{l}\text { Local strains } \\
\text { Three strains }\end{array}$ & $\begin{array}{l}\text { Titres } 32,256 \text {, and } 256 \\
\text { respectively, unaffected } \\
\text { by } H . \text { aegyptius serum } 1: 40\end{array}$ & No agglutination \\
\hline $\begin{array}{l}53 \text { strains } \\
10 \text { strains }\end{array}$ & $\begin{array}{l}\text { No agglutination } \\
\text { No agglutination }\end{array}$ & $\begin{array}{l}\text { No agglutination } \\
\text { Floccular agglutination in } \\
\text { tests and control tubes }\end{array}$ \\
\hline 10 strains & No agglutination & $\begin{array}{l}\text { Agglutination in tests but not } \\
\text { in control tubes. Further } \\
\text { details given below }\end{array}$ \\
\hline
\end{tabular}

Bacterial Agglutination Test
(H. aegyptius serum diluted 1

Granular type of agglutination,

No agglutination

y H.aegyptius serum 1:40

No agglutination

details given below 
patients who were simply described as having eye discharges.

Although many hundreds of eye swabs from newborn babies were examined, only three haemophilus strains (none of them capsulated) came from such sources.

Very few of our patients were suffering from acute conjunctivitis.

\section{DISCUSSION}

We do not feel justified in drawing any firm conclusions from the morphological distinctions between the $H$. aegyptius $180 \mathrm{a}$, for many years a laboratory strain, and our freshly isolated strains. The presence of capsules with the serological characters of known $H$. influenzae strains provides surer ground for saying that at least some of our strains were not $H$. aegyptius, though it is not inconceivable that strains of this species exist which share the capsular antigens of $H$. influenzae.

Indole production was quoted by Cowan and Steel (1965), on the basis of the report by Pittman and Davis (1950), as one of the criteria for distinguishing these two species. Pittman and Davis did not find that it was a reliable differentiating character; all of their $\boldsymbol{H}$. aegyptius strains gave negative reactions, but only $19(76 \%)$ of the eye haemophilus strains which they classified as $H$. influenzae gave positive reactions. On this evidence the indole reactions of our strains are compatible with their all being $H$. influenzae.

Davis et al (1950) found the haemagglutination test to be a valuable means of differentiating $H$. aegyptius from $H$. influenzae. Its validity for this purpose was challenged by Ivler, Preston, and Portnoy (1963) on the grounds that even $H$. influenzae strains can cause haemagglutination if the procedure is suitably modified. However, a test does not cease to be of value in differentiation merely because it measures a quantitative rather than an absolute difference between species. Using their original version of the test, Davis and his colleagues (1950) found that $H$. influenzae strains consistently gave negative results, whereas 27 out of their $28 \mathrm{H}$. aegyptius strains agglutinated human red cells and the identity of the one strain that failed to do so was somewhat suspect in that it gave only weak agglutination reactions with $H$. aegyptius antiserum. Haemagglutination by the $H$. aegyptius strains was inhibited in the presence of dilute $H$. aegyptius antiserum. Three of our strains caused haemagglutination, but they cannot be classified as $H$. aegyptius on this evidence alone in the face of the failure of $H$. aegyptius antiserum either to inhibit their haemagglutinating ability or to agglutinate suspensions of them.

The $H$. aegyptius 180 a antiserum supplied to us by Dr Pittman was the most 'polyvalent' of the antisera for that species prepared by her and her colleagues, and agglutinated all of their $\boldsymbol{H}$. aegyptius strains. However, its titre for a few of them was low (20 or 40) and it might well have failed to detect such strains in the conditions of our tests. We are therefore not able to say that our agglutination test results exclude the possibility that there were $H$. aegyptius strains among the 76 tested by us; we can say only that we have no positive evidence, from these or any of our tests, for the presence of such strains.

Indeed, nothing in our findings indicates that the haemophili which we isolate from eyes differ from those of the respiratory tract and cannot be classified as $H$. influenzae, or possibly as $H$. para-influenzae, but that is a distinction that we have not pursued for reasons discussed by Turk and May (1967). However, our material was far from being comparable with that of the workers whose reports are quoted in our opening paragraph. It may be that $H$. aegyptius is exclusively associated with infectious conjunctivitis, and even in this country a study of haemophili from an outbreak of that condition might yield results radically different from ours.

The evidence for an association between haemophili and lachrymal duct obstruction was an unexpected byproduct of this study. It clearly demands further investigation. We find it particularly interesting because of the well known role of haemophili in ducts of another type-the bronchi-when these are the site of chronic disease and impaired drainage. However, the haemophili which cause trouble in the bronchi are virtually always non-capsulated, and type b capsulated strains are rarely involved there, despite their high level of pathogenicity in other situations (Turk and May, 1967). The number of type b strains that we isolated from the eyes of children with certain or probable lachrymal duct disease suggests that they may be pathogens in this situation.

We are indebted to colleagues in both laboratories, notably Miss J. Dutton, FIMLT, for help in isolation of the haemophili; to Miss C. Morland for her invaluable help in developing and carrying out the other technical procedures; to Mr J. M. L. Howat, ophthalmic surgeon, for his interest and encouragement; and to the Peel Medical Research Trust for financial support of the study of haemophili.

\section{REFERENCES}

Cowan, S. T., and Steel, K. J. (1965). Manual for the identification of Medical Bacteria, p. 67. Cambridge University Press, Cambridge. Davis, D. J., and Pittman, M. (1950). Amer. J. Dis. Child . 79, 211. 
, and Griffitts, J. J. (1950). J. Bact., 59, 427.

Huet, M. (1956). Ann. Inst. Pasteur 90, 106.

Ivler, D., Preston, H. M. and Portnoy, B. (1963). Proc. Soc. exp. Biol. $(N . Y), 114,232$.

Koch, R. (1883). Wien. med. Wschr., 33, 1548.

Leidy, G., Jaffee. I., and Alexander, H. E. (1965). Ann. N.Y. Acad. Sci., 118, 671 .
Olitski, A. L., and Sulitzeanu, A. (1959). J. Bact., 77, 264.

Pittman, M., and Davis, D. J. (1950). Ibid., 59, 413.

Pfeiffer, R. (1892). Dtsch. med. Wschr., 18, 28.

Turk, D. C., and May, J. R. (1967). Haemophilus influenzae: Its Clinical Importance. English Universities Press, London.

Weeks, J. E. (1886). Arch. Ophthal. (Chic)., old ser. 15, 441. 